\title{
Use of aerosols in bronchiectasis patients
}

\author{
R.W. Dal Negro, C. Micheletto, S. Tognella
}

ABSTRACT: Use of aerosols in bronchiectasis patients. R.W. Dal Negro, C. Micheletto, S. Tognella.

Bronchiectasis is a chronic respiratory disease which recognises different etiologies, and characterised by persistent cough, bronchial hypersecretion, airway colonisation with Gram-negative pathogens; frequent infectious exacerbations; progressive lung function decline, and poor quality of life.

Several therapeutic strategies are used for managing bronchiectasis, and nebulised medications are regarded with great and ever increasing interest because they allow the direct medication of targets airway structures, higher concentrations of the drug employed, and much less systemic effects.

In general terms, the available therapeutic strategies lead to different results depending of whether bronchiectasis are related to cystic fibrosis or not. The effects of the main classes of drugs for aerosol delivery in bronchiectasis patients have been reviewed and updated.

Further research is needed in order to ameliorate therapeutic interventions in bronchiectasis, both in terms of new molecules and aerosol formulations to use, and of systems able to optimize drug delivery and drug effectiveness. Monaldi Arch Chest Dis 2011; 75: 3, 185-193.

Keywords: Bronchiectasis, Aerosols, Nebulised drugs, Mucolitics, Osmolar agents, Bronchodilators, Inhaled corticosteroids, Aerosol gene transfer, Nebulised antibiotics.

Lung Dept., Orlandi General Hospital, ULSS22 Regione Veneto, Bussolengo, Verona, Italy.

Correspondence: Dr. Roberto W. Dal Negro, Lung Dept., Orlandi General Hospital, ULSS22 Regione Veneto, 37012 Bussolengo,Verona, Italy; E-mail: rdalnegro@ulss22.ven.it

Bronchiectasis is a chronic respiratory condition characterised by a permanent abnormal dilatation of one ore more large bronchi $(>2 \mathrm{~mm}$ in diameter) due to destruction of elastic and muscular components of the airway wall. The morphological pattern of bronchiectasis can vary widely and contributes to their description as cylindrical, fusiform, or cystic; their extension can be limited to a small region of one lung or diffuse within both lungs.

Bronchiectasis can be congenital or acquired, and there are several known causes of this condition: broncho-pulmonary infection (viral, bacterial, or fungal) causing necrotising inflammation; tuberculosis; aspiration of chemical substances; repeated aspiration of gastric fluid; cystic fibrosis; bronchial asthma; COPD (Chronic Obstructive Pulmonary Disease); sinusitis; ciliary immobility disorders, and bronchial compression (such as due to hilar lymphnodes or tumour masses; endobronchial neoplasms; foreign bodies). Predisposing condition are primary and acquired immunodeficiencies which affect pulmonary host defenses.

Compared to previous decades, prevalence of bronchiectasis is declining in recent years; at present the high-resolution computed tomography represents the key diagnostic procedure, and the role of surgery is palliative and limited to resection of the most affected segments [1, 2].

Even if signs and symptoms of bronchiectasis depend on its extension and severity, the hallmarks of this condition are the presence of chronic cough; sputum production, bronchial bleeding, and recurrent pneumonia in affected regions. Regardless the underlying aetiology, the altered rheology of bronchial secretions and their inefficient clearance due to the physiological and anatomical abnormalities in specialised structures of bronchial walls lead to superimposed chronic infections in the majority of bronchiectasis patients and to exacerbations frequently repeated.

Several approaches had been used in the therapeutic management of bronchiectasis, from the traditional to the most recent ones, and different routes for drug administration had been tried in order to optimise clinical outcomes.

Administration of drugs via the inhalation route is regarded with great and ever increasing interest also in respiratory diseases other than bronchial asthma and COPD (which represent the most consolidated targets of this way for delivering medicines), and particularly in bronchiectasis.

The main reasons for the increasing interest in aerosolized therapeutics are: a much more direct and effective action of the drug on structural targets, also in the deep lung; the need of a much lower (several-fold) dose than that of the systemic drug for achieving the same therapeutic response; and a much lower bioavailability with a dramatically lower incidence of side effects [3-5].

Table 1 summarises the main characteristics of all inhalation devices quoted in the present review. It should be noted that when the particle size varies from $<6 \mu$; to $2-6 \mu$, or to $<2 \mu$, the site of the therapeutic target changes substantially (such as, mouth/oesophageal region, rather than the upper/cen- 
Table 1. - Main characteristics of inhalation devices quoted in the present review

\begin{tabular}{|c|c|c|c|c|c|}
\hline Devices & $\begin{array}{l}\text { Particle } \\
\text { Size }(\mu) \\
<6 \mu \text { : clinical } \\
\text { efficacy }\end{array}$ & $\begin{array}{c}\text { Oral } \\
\text { deposition } \\
(\%)\end{array}$ & $\begin{array}{c}\begin{array}{c}\text { Lung } \\
\text { deposition } \\
(\%)\end{array} \\
\text { (\%) }\end{array}$ & $\begin{array}{c}\text { Intrinsic } \\
\text { Resistance } \\
\left({\left.\text { Mbar } 1 / 2 / \text { Imin }^{-1}\right)}^{-1}\right.\end{array}$ & $\begin{array}{l}\text { Inspiratory } \\
\text { Flow } \\
\text { Dependency }\end{array}$ \\
\hline \multicolumn{6}{|c|}{ MDIs (metered dose inhalers) } \\
\hline $\mathrm{CFC}$ & $4-8$ & $60-80$ & $5-10$ & & ++ \\
\hline HFA & $\sim 1$ & 20 & $50-55$ & & \pm \\
\hline \multicolumn{6}{|c|}{ DPIs (dry powder inhalers) } \\
\hline Diskhaler & $4-6$ & 40 & $10-15$ & $<5$ & +++ \\
\hline Turbohaler & $3-5$ & 30 & $10-30$ & $5-10$ & +++ \\
\hline Diskus & $3-5$ & 30 & $30-40$ & $5-10$ & \pm \\
\hline HandiHaler & $4-6$ & & & $<5$ & +++ \\
\hline Jet nebulisers & $\begin{array}{l}\text { Variable: } \sim 3-4 \text { inversely } \\
\text { related to the gas } \\
\text { flow rate and temperature }\end{array}$ & $\sim 40$ & $20-40$ & & +++ \\
\hline Ultrasonic nebulisers & $\begin{array}{l}\text { Variable: a direct } \\
\text { function of the length } \\
\text { of the waves produced } \\
\text { on the liquid surface }\end{array}$ & $\sim 40$ & $20-40$ & & ++ \\
\hline
\end{tabular}

tral airways, or the peripheral airways. It should be further noted that the performance of each device also depends on the drug class used (antibiotics; steroids; bronchodilators; mucoactive drugs; enzymes, etc.), independently of its intrinsic characteristics.

Indeed, there are several classes of inhaled medications with different properties and indications which are daily prescribed, or still in development, for treating bronchiectasis (tab. 2).

\section{A - Mucoactive agents}

The aim of treating bronchiectasis with inhaled mucolitic agents is to ameliorate tracheobronchial clearance by affecting rheologic properties of secretions. Subjects with bronchiectasis, whether related or not to cystic fibrosis, produce viscous and muco-purulent secretions that can lead to cellular necrosis and airway damage if not treated, because endobronchial mucus represents the major cause of microbial colonisation, being mucus clearance delayed substantially.

The most studied compound of this class is recombinant human DNase, which has been evaluat-

Table 2. - Medication for aerosol delivery in bronchiectasis
A - Mucoactive agents
B - Osmolar agents
C - Anti-inflammatory agent
D - Bronchodilators
E - Aerosol gene transfer
F - Antibiotics

ed in randomised controlled trials carried out on stable patients with bronchiectasis not due to cystic fibrosis. DNA release from neutrophilic cells is suggested to underlie the increase in viscosity of bronchial secretions while inhaled recombinant human DNase was supposed to affect secretions by lowering their viscosity and minimizing mucus plugs and local inflammation. A multicenter study was carried out in 23 Centres in North America, Great Britain and Ireland and 349 subjects with idiopathic bronchiectasis (that is not related to $\mathrm{CF}$, such as a peculiar condition characterised by a genetic alteration in membrane osmolality; persistent airway infection due to a dramatic increase in viscosity of purulent airway secretions, being also their clearance from the airways extremely reduced) were recruited [5]. Subjects received aerosolised recombinant human DNase or placebo twice daily for 24 weeks. Primary and secondary end points were the exacerbation rate and mean $\%$ change in Forced Expiratory Volume in one second $\left(\mathrm{FEV}_{1}\right)$. Exacerbations were defined as abnormalities in four of the following nine symptoms, signs, or laboratory findings: 1) change in sputum characteristics (such as: volume, consistency, colour, or hemoptysis); 2) increased dyspnoea; 3) increased cough; 4) occurrence of fever; 5) occurrence or increase in wheezing; 6) decreased exercise tolerance or fatigue: 7) a $10 \% \mathrm{FEV}_{1}$ or Forced Vital Capacity (FVC) drop from previous stabilized values; 8) radiographic suggesting a new pulmonary process; 9) changes in chest sounds [6]. A second placebo-controlled study was carried out in the aim of assessing both efficacy and safety of the same compound administered via inhalation 2.5 mg twice daily or once-daily to adults with idiopathic bronchiectasis for a 14-day period. Changes 
in spirometric indices and quality of life (such as, the own patient's-perceived health status as assessed by means of a questionnaire which investigated seven domains of well-being: cough, dyspnoea, limitation in daily activities, emotional wellbeing, fatigue, disabled days, and perceived overall health [6]) were the end points, together with the ability of sputum clearance (such as, the capability of ciliated cells embedded within the bronchial epithelium to clear airway secretions upwards from the bronchial tree: this physiological function is strongly reduced due to the presence of ciliary dyskinesia in these circumstances) before and after treatments [7]. Unfortunately no significant benefit was obtained in subjects of both trials and no significant $\mathrm{FEV}_{1}$ chance was also confirmed in these patients. Nevertheless, inhaled DNase proved some long-lasting (over a 2-yr period) spirometric improvement in patients with bronchiectasis due to cystic fibrosis, even though in the absence of any significant reduction of infectious events [8].

A further study carried out on fifty-two children with cystic fibrosis proved that dornase alpha is equally effective when assumed before or after physiotherapy, but when subjects are colonized with pseudomonas aeruginosa the effect on their $\mathrm{FEV}_{1}$ is more pronounced if dornase alpha is delivered after physiotherapy [9].

In addition $\mathrm{N}$-acetylcysteine has been studied in small samples of subjects with cystic fibrosis for short periods. Only small improvements in lung function were measured over a twelve-week course, and its long-term use is not regarded as the treatment of choice [10].

A more recent trial further investigated efficacy and safety of aerosolised $\mathrm{N}$-acetylcysteine (twelve puffs, $24 \mathrm{mg}$ ) versus matched placebo in small samples of patients with cystic fibrosis. Lung function was equally unaffected by the active drug and placebo even though a dose-dependent decrease in sputum visco-elasticity (such as, viscosity and elasticity, which are important rheologic determinants of airway mucociliary transport) was found with the former treatment after four hours [11].

\section{B - Osmolar agents}

Mucus retention in the lung is a characteristic feature of bronchiectasis which greatly contributes to facilitate bacteria colonisation within the airways; to elicit the host neutrophilic response, and to enhance airway damage due to protease activity.

The induction of changes in osmolality of bronchial secretions represents a therapeutic approach since long ago. In particular, humidification of inspired air (or oxygen) is a technique frequently used in order to ameliorate sputum retention. The effects of cold water and jet nebulising humidifiers were investigated in seven adult (4164 years) with bronchiectasis $\left(\mathrm{FEV}_{1} 29-76 \%\right.$ predicted) during chest physiotherapy according to a randomized controlled design. Sputum clearance was assessed by means of a radio-aerosol of hu- man serum albumin millimicrospheres labelled with Technetium 99m detected by serial gamma camera images [12]. Compared to physiotherapy alone, when humidification was added to physiotherapy, a significant increase in total wet weight of sputum collected and a significant increase in total radiolabel clearance were assessed (both $p<0.05)$.

Clinical trials have proved that hypertonic saline (3-14.4\%) and mannitol (300-400 mg) are able to increase clearance of mucus acutely in patients with bronchiectasis. A reduction in viscoelastic properties, in surface tension and spin ability, and an increase in mucus hydration were also confirmed with these agents. Moreover, inhalation of mannitol $400 \mathrm{mg}$ twice daily for two weeks improved quality of life significantly in the same patients [13].

Furthermore, inhalation of hyperosmolar saline $7 \%$ four times daily for two weeks proved effective in improving mucus clearance and lung function in cystic fibrosis, and this therapeutic performance was maintained over a twelve month period without any change in the bacterial density.

It is now accepted that inhalation of hypertonic saline is able to accelerate tracheobronchial clearance also in bronchiectasis, likely because it causes a liquid influx into the airway lumen, thus affecting rheology of airway secretion at more favourable regimens and facilitating mucociliary clearance. Also inhalation of dry powder mannitol confirmed a similar mechanism of action [14]. In a recent review, hyperosmolar agents were confirmed as effective therapeutic options which are able to affect both the volume and the rheology of airway secretions [15].

\section{C - Anti-inflammatory agents}

Inhaled corticosteroids (ICS) are commonly prescribed to treat airway inflammation, particularly in asthma and COPD patients.

ICS (bechomethasone; budesonide, fluticasone) have also been used in idiopathic bronchiectasis in order to assess their ability in preventing exacerbations and improve lung function. Two short-term trials ( 6 and 4 weeks respectively) were carried out according to a randomised, placebocontrolled design [16;17]. Unfortunately, both studies (with bechlomethasone and fluticasone, respectively) did not show any significant effect on spirometric indices (such as, FEV 1 , FVC, PEFR (Peak Expiratory Flow Rate), RV (residual Volume), and diffusing capacity for CO - carbon dioxide) and main respiratory symptoms (such as, sputum production, cough, wheezing, and dyspnoea) when low dosed.

Despite ineffectiveness on lung function, fluticasone propionate $500 \mathrm{mcg}$ twice daily, but not placebo, proved significantly effective in lowering sputum leukocyte density $(\mathrm{p}<0.05)$ and concentration of some pro-inflammatory mediators (such as, IL-1 $\beta$, IL-8, and $\mathrm{LTB}_{4}$ ) in bronchial secretions from twenty-four patients with stable idiopathic bronchiectasis, even though their absolute concen- 
tration still remained high also after fluticasone [17]. Other studies showed that if low-dose ICS had no effects on sputum, higher-dose ICS (such as, bechlomethasone dipropionate $1.5 \mathrm{mg}$ daily or budesonide $1.6 \mathrm{mg}$ daily) tends to improve sputum volume, respiratory symptoms, lung function, and bronchial hyperreactivity, particularly in adult patients with bronchiectasis due to cystic fibrosis $[16,18]$.

As a substantial and persistent neutrophil recruitment has a relevant pathogenic role in bronchiectasis and contributes greatly to sustain the progressive functional and structural damage of the airways, the strategic relevance of this therapeutic approach in terms of a possible disease modifier intervention still remains to be clarified and it should be assessed more precisely in dedicated long-term trials.

In fact, in a recent trial, fluticasone $500 \mathrm{mcg}$ twice daily or matched placebo were randomly administered to eighty-six patients with bronchiectasis according to a double-blind design for a fiftytwo week period. Of the seventy-two patients who completed the study (thirty-five and thirty-eight in the two arms, respectively), significantly more patients receiving fluticasone than placebo improved their twenty-four-hours sputum volume $(\mathrm{p}<0.03)$, but their $\mathrm{FEV}_{1}$, FVC, sputum purulence, and exacerbation rate proved unchanged. The exacerbation rate was only improved in the subset of patients with Pseudomonas aeruginosa infection in whom also sputum volume was particularly improved after fluticasone [19]. A recent Cochrane review carried out on six adult studies fulfilling inclusion criteria (a sample of 278 subjects) indicated that there is insufficient evidence to recommend the daily use of ICS in adults with stable bronchiectasis even if their lung function, quality of life, and sputum volume were ameliorated significantly with high dose ICS [20]. The net improvement obtained in patients with difficult-to-control clinical conditions had to be balanced with side effects (the occurrence, or the enhancement, of hyper-glycaemia; hormonal disorders, systemic blood hypertension, impairment of bone metabolism, skin thinning and bruising, lower lung infections, etc.), registered with these doses [20].

\section{D - Bronchodilators}

As randomised controlled trials aimed to assess the true effectiveness of bronchodilators on clinical outcomes and mucociliary clearance are still missing or their level of evidence is quite poor, and bronchiectasis are frequently characterised by a persistent airflow obstruction, inhaled bronchodilators (such as, $\beta_{2}$ adrenoceptor agonists and anti-cholinergics) are usually prescribed empirically to these patients [21-24].

Inhaled short-acting $\beta_{2}$-adrenoceptor agonists have been used in bronchiectasis with the aim of affecting sputum clearance. The effects of nebulised saline and terbutaline $5 \mathrm{mg}$ were measured by using Technetium 99m labelled human albumin microspheres, and compared in eight adults with sta- ble bronchiectasis. Even if the mechanism was not clarified, nebulised terbutaline enhanced significantly radio-aerosol clearance from the whole lung when added immediately before chest physiotherapy [25]. Other studies tend to pinpoint that in adult patients with bronchiectasis, only those individuals who are characterised by a substantial bronchial hyper-responsiveness respond significantly to prolonged bronchodilator treatments [26, 27].

Also the effects of anticholinergics in both acute and stable bronchiectasis have to be further assessed an no formal recommendation can be made on the basis of the present evidence [28-29].

It should be noted that the synergistic therapeutic value of adding different therapeutic options via inhalation route (such as, short-acting $\beta_{2^{-}}$ adrenoceptor agonists, DNase, hyperosmolar agents, and antibiotics) to the same patient several times daily has never been demonstrated also in children

\section{E - Aerosol gene transfer}

The research in aerosolised medications has greatly expanded in the last two decades both in terms of innovative drug formulations and device technologies specifically targeting the systemic drug delivery, vaccination, and gene therapy. In other words, inhalation is increasingly regarded as a therapeutic route also for drugs which recognise their targets outside the lung and that should be administered safely for a long period of time.

Gene therapy, such as the treatment of any disorder by means of the transfer of genetic information, nowadays represents a high priority topic of research and the lung is supposed to represent one of the major targets for genetic diseases, and particularly for cystic fibrosis [30, 31].

As cystic fibrosis is an autosomal recessive genetic disease, following the cloning of the cystic fibrosis transmembrane regulator gene (CFTR), the opportunity to deliver CFTR directly to the lung became a priority therapeutic option to investigate and develop with the aim of minimising the effects of the underlying chloride defect which is peculiar for the disease.

In general terms, the ideal vector for gene delivery would be characterised as following: have adequate capacity to carry genetic information being undetectable by the host's immune system; not inducing inflammatory reactions; be safe to the host; be able to correct the basic defect; have a long duration; be re-administered safely [32].

Viral and non-viral vectors were used, even though the former led to host-antigen-specific immune responses caused by replication-deficient viral vectors, and the latter to be more valued presently. In this class of vectors, promising results in early phase trials were obtained with cationic liposome/plasmid DNA complexes and compacted DNA nanoparticles as carriers of CFTR gene, even though the therapeutic effect proved too low and of short duration [33].

Research for improving the limited gene transfer efficiency of current vectors is ongoing, and 
new substrates are continuously investigated in order to overcome the barriers which are limiting gene delivery and deposition into the lung at present [34]. Actually, DNA delivery represents per se a new challenge due to the need to target specific regions and tissues into the lung should lead to develop new formulations of inhaled substrates together with more specific and suitable devices in order to optimise lung deposition of these particular materials [35].

\section{F - Antibiotics}

Antibiotic delivery via inhalation route represents the most investigated therapeutic option in bronchiectasis since long ago. Further the systemic, the inhaled administration of antibiotics was widely investigated as a way to prevent (or/and cure) exacerbations in patients with bronchiectasis, being the goal that of interrupting the vicious circle of bacterial colonization which causes inflammation and progressive tissue injury. The main reasons for the increasing interest in nebulised antibiotics to deliver to bronchiectasis patients are: 1) the administration of an antibiotic via the inhalation route ensures higher (several folds) concentration of the drug at the site of infection; 2) its systemic concentration is dramatically lower; 3 ) related toxicity is significantly minimised [36].

Several antibiotic molecules were investigated in the last decades from this point of view; different aerosol treatments were targeted towards specific and less specific pathogens underlying bronchiectasis morbility, and nebulised has been also used in association with systemic antibiotics in patients with bronchiectasis.

More than fifty years ago, the first attempts to nebulised antibiotics were carried out with polimixins and penicillin $\mathrm{G}$, and soon after with gentamycin in $\mathrm{CF}$, but their use was limited because $\mathrm{pH}$ and ingredients of solutions used at that time induced significant side effects (i.e., gastrointestinal disorders, but effects mainly due to the ototoxicity and nefrotoxicity of ceftazidime and systemic aminoglycosides).

Nearly twenty-years ago, nebulised amoxicillin (500 mg twice daily) was given to six patients with purulent bronchiectasis for four months following the therapeutic failure with amoxicillin assumed orally (3g twice daily). Sputum volume and purulence were significantly reduced after aerosolised amoxicillin and peak expiratory flow rate increased $(p<0.05)$, thus suggesting that the aerosolised antibiotic consented higher and more effective local concentrations into the lung [37].

In more recent times, ticarcillin; ceftazidime and carbenicillin were also used at different dosages $[13,15,38]$ in hypertonic solutions with variable results, but frequent adverse events were occurring (such as cough and sudden bronchoconstriction, and sometimes fever) in those cases. Also Amphotericen B was used in cystic fibrosis but its nebulisation was quite poor, mainly due to the colloid pattern of suspension. Colistine sulphome- thane was extensively used in cystic fibrosis even though it tends to foam significantly during nebulisation, with relevant problems in defining the active respiratory dose for patients [38]. To note that one of the major factors influencing the efficacy and the effectiveness of aerosolised antibiotics in bronchiectasis is the pattern of drugs deposition into the lung and their particle size because they can affect the capability of aerosols to penetrate into the lung and to reach the right tissue targets significantly.

In general, some controlled studies investigating the potential benefits of nebulised antibiotics in patients who became colonised by Pseudomonas Aeruginosa, showed that the pathogen was eradicated from their sputum in one/third of patients, and more than $60 \%$ of subjects showed their clinical condition improved [39].

A Cochrane review has pooled (even though different in their study design) six randomised controlled studies carried out in patients with idiopathic (i.e. unrelated to $\mathrm{CF}$ ) bronchiectasis. In these patients, even if facilitating the emergence of resistant organisms, the long-term treatment with antibiotics proved effective in lowering sputum volume and purulence, but had limited results in terms of frequency of exacerbations and natural history of the disease both in adults and in children [40, 41].

Aerolised gentamycin $40 \mathrm{mg}$ twice daily, but not $0.45 \%$ saline, has proved effective in ameliorating lung function and reducing hypersecretion and inflammatory neutrophil activity in twentyeight adults with idiopathic bronchiectasis, thus preventing myeloperoxidase -mediated airway injury [42].

In children with non-CF bronchiectasis treated with gentamycine $80 \mathrm{mg}$ daily in saline by means of a PARI LC plus nebuliser and a PARI Turboboy $\mathrm{N}$ compressor, lung function was not affected, but gentamycic achieved bactericidal concentrations in sputum with negligible systemic absorption [43]. Furthermore, a pilot study suggested that for treating Pseudomonas Aeruginosa infections susceptible to gentamycin in patients with bronchiectasis related or not to $\mathrm{CF}$, gentamycin delivered via a DPI (Dry Powder Inhaler) device should be as effective as that nebulised by means of usual jet nebulizers, and more acceptable to patients despite the delivery of a 7-fold lower dose to the airways [44].

It is well known that Pseudomonas Aeruginosa represent the most common pathogen colonising and infecting airways in bronchiectasis, particularly those related to $\mathrm{CF}$.

In general, it should be considered that these pathogens can only be eradicated in the early stages of colonisation, and that reduction in bacterial density is the main goal to pursue in chronic colonisation or exacerbations, regardless the molecule used [45]. In a placebo controlled, doubleblind, randomised multicenter study carried out on $22 \mathrm{CF}$ patients treated with tobramycin $80 \mathrm{mg}$ b.i.d or placebo for a twelve-month period the time to conversion from a positive to a negative Pseudomonas Aeruginosa respiratory culture was 
significantly shorter in tobramycin-treated patients $(p<0.05)$, even though lung function did not change [46].

There is strong evidence in favour of using aerosol antibiotics for treating gram-negative infections (particularly those due to Pseudomonas Aeruginosa) in CF, while regular aerosolised tobramycin or colistin have been shown to decrease significantly exacerbations and bacterial counts, and to improve lung function over-time [47].

Modern aersolised aminoglycosides are generally well tolerated also during long-term treatments, and serious adverse event are episodic and mainly related to the physical properties of solution employed or to the presence of preservatives in the solutions [48]. Not all devices (jet rather than ultrasonic nebulizers) lead to comparable therapeutic performances: particularly in the case of aerosolised aminoglycosides the role of the device used for delivering the antibiotic solution and that of the mass median aerodynamic diameter (MMAD) of the particles produced play a critical role and can affect lung deposition greatly. In bronchiectasis, and in particular in those related to $\mathrm{CF}$, the deranged airway geometry represents per se a barrier hampering an efficient and homogeneous drug deposition into the lungs, and most fitting devices should then be used.

Preservative free solution and solutions specifically prepared for the lung in terms of osmolality, $\mathrm{pH}$, and possible monodispersed particle size represent the cornerstones for an effective and safe antibiotic treatment via the inhalation route in bronchiectasis, particularly in CF. On the other hand, the empiric aerosilisation of parenteral antibiotics produces chemical changes in the mole- cules of the drug which lead to significant variations in the physical properties of the substance, to unexpected low effectiveness of treatment, and to unwanted side effects frequently.

Tobramicine Nebulised Solution (TNS) has an Osmolality between $158-183 \mathrm{mOsm} / \mathrm{kg}$, while chloride ion concentration is $75 \mathrm{mM}$, with a $\mathrm{pH}=6$, and $\mathrm{MMAD}=4$ : in other words, in the ideal range for nebulised antibiotic solutions. Tobramicine also represents the first specific formulation for nebulisation which can be delivered via a designated reusable nebuliser (PARI LC Plus) in CF $[36,49]$.

In fact, the most convincing data (in terms of increase in respiratory function; decrease of sputum density; admission rate, and need of systemic antibiotics) supporting the use of aerosol antibiotics has been generated with Tobramycin solution (TOBI, Chiron Corp.) for maintenance treatment (4-8-fold greater activity than amikacin and gentamicin), and with a sputum peak concentration $>15$-fold higher than with parenteral tobramycin in cystic fibrosis [50]. This evidence has also been recently confirmed in a study carried out in thirteen patients with severe COPD, colonized by Pseudomonas Aeruginosa multiresistant to oral/intravenous specific antibiotics and treated with nebulised tobramycine $300 \mathrm{mg}$ twice daily for two weeks. In these patients, levels of eosinofilic cationic protein, IL-1 $\beta$, IL- 8 , and tumour necrosis factor (TNF- $\alpha$ ) were significantly lowered in spontaneous bronchial secretions, together to the bacterial density after active treatment, thus emphasizing also the role of nebulised tobramycin in lowering the inflammatory impact of pseudomonas aeruginosa colonising severely chronically obstructed airways [51].

Table 3a. - Main outcomes obtained with different classes of aerosolized non-antibiotic drugs in patients with bronchiectasis, related or unrelated to cystic fibrosis (CF) (see text)

\begin{tabular}{|c|c|c|c|}
\hline Class of drug & outcome & CF unrelated & CF related \\
\hline \multicolumn{4}{|l|}{ Mucoactive } \\
\hline • DNase & $\begin{array}{c}\text { FEV }_{1} \\
\text { exacerbations }\end{array}$ & $\begin{array}{l}- \\
-\end{array}$ & $\begin{array}{l}\Delta \\
\pm\end{array}$ \\
\hline - NAC & $\begin{array}{c}\mathrm{FEV}_{1} \\
\text { exacerbations }\end{array}$ & $\begin{array}{l}- \\
-\end{array}$ & $\begin{array}{l}- \\
-\end{array}$ \\
\hline \multicolumn{4}{|l|}{ Osmolar agents } \\
\hline $\begin{array}{l}\text { - water humidifiers } \\
\text { - hypertonic saline } \\
\text { - mannitol }\end{array}$ & $\begin{array}{l}\text { Mucus clearance } \\
\text { Mucus clearance } \\
\text { Mucus clearance }\end{array}$ & $\stackrel{ \pm}{\Delta}$ & $\stackrel{ \pm}{\Delta}$ \\
\hline \multicolumn{4}{|l|}{ Anti-inflammatory } \\
\hline - ICS & $\begin{array}{c}\mathrm{FEV}_{1} \\
\text { Mucus clearance } \\
\text { Sputum inflammation } \\
\text { Exacerbations }\end{array}$ & $\begin{array}{l}- \\
\pm \\
\pm \\
-\end{array}$ & $\begin{array}{l}\boldsymbol{\Delta} \text { (high dose }) \\
\boldsymbol{\Delta} \text { (high dose }) \\
\boldsymbol{\nabla} \text { (high dose }) \\
\pm \text { (high dose })\end{array}$ \\
\hline Bronchodilators & $\begin{array}{l}\text { FEV }_{1} \\
\text { Mucus clearance }\end{array}$ & $\begin{array}{c}\Delta(\mathrm{BHR}) \\
\pm\end{array}$ & $\begin{array}{c}\Delta(\mathrm{BHR}) \\
\pm\end{array}$ \\
\hline Aerosol gene transfer & Chloride defect & & \pm \\
\hline
\end{tabular}


Table 3b. - Main outcomes obtained with antibiotics in patients with bronchiectasis, related or unrelated to cystic fibrosis (CF) (see text)

\begin{tabular}{|c|c|c|c|}
\hline Class of drug & outcome & CF unrelated & $\mathrm{CF}$ related \\
\hline Antibiotics (in general) & $\begin{array}{l}\text { Mucus clearance } \\
\text { Sputum purulence } \\
\text { Exacerbations }\end{array}$ & $\begin{array}{l}\Delta \\
\boldsymbol{\nabla} \\
\pm\end{array}$ & $\begin{array}{l}\Delta \\
\boldsymbol{\nabla} \\
\pm\end{array}$ \\
\hline - gentamycine & $\begin{array}{l}\text { Mucus clearance } \\
\text { Lung function } \\
\text { Sputum inflammation } \\
\text { Bacterial density }\end{array}$ & $\begin{array}{l}\Delta \\
\pm \\
\pm \\
\nabla\end{array}$ & \\
\hline - tobramycin & $\begin{array}{l}\text { Mucus clearance } \\
\text { Lung function } \\
\text { Sputum inflammation } \\
\text { Bacterial density } \\
\text { Hospitalizations } \\
\text { Adverse events }\end{array}$ & $\begin{array}{l}\Delta \\
\nabla \nabla \\
\nabla \\
\nabla \\
\nabla\end{array}$ & $\begin{array}{l}\Delta \\
\nabla \nabla \\
\nabla \nabla \\
\nabla\end{array}$ \\
\hline
\end{tabular}

As pulmonary conditions, disease progression, and the physical and biochemical patter of secretions are similar in bronchiectasis related or not-related to $\mathrm{CF}$, the use of aerosolised tobramycin became widespread even though clinical outcomes (in particular lung function) can vary depending if bronchiectasis are due to CF or not [47]. In any event, there is a consolidated evidence that tobramycin concentration in sputum is directly related to treatment duration, being the clinical value of repeated long-term treatments with this aerosol solution, particularly in bronchiectasis related to $\mathrm{CF}$, thus emphasized [38, 40, 41, 52, 53].

Main outcomes obtained with each class of aerosolised drugs in patients with bronchiectasis, related or unrelated to $\mathrm{CF}$, are summarised in tab. $3 \mathrm{a}$ and $3 \mathrm{~b}$.

\section{Conclusion and future perspectives}

Bronchiectasis is a chronic respiratory disease which recognises different aetiologies and is characterised by chronic cough; exaggerate muco-purulent or purulent sputum production; recurrent airway infections and/or pneumonia; progressive decline in lung function, and poor quality of life. The therapeutic approach to bronchiectasis via the inhalation route has been increasingly preferred because medications used reach tissular targets into the airways much more directly, with higher concentrations, and to a much less systemic biovailability.

Nevertheless, several factors can limit both efficacy and effectiveness of aerosol treatments: the extension of lesions; the etiology of bronchiectasis;

\section{Key issues in Bronchiectasis}

- Bronchiectasis, is a chronic respiratory disease which is still regarded as an orphan condition, in particular when unrelated to $\mathrm{CF}$.

- The increasing preference for a therapeutic strategy based on the delivery of nebulised drugs stems from the evidence that they consent a more direct and highly concentrated medication of airways, to much less systemic effects.

- Several classes of drugs can be administered via inhalation (such as, mucoactive, osmolar agents; and anti-inflammatory agents; bronchodilators; aerosol gene transfer; antibiotics), but different therapeutic effects can be obtained depending of the extension and the etiology of bronchiectasis.

- Mucolitics, osmolar agents, ICS (only when high dosed), are therapeutic options mainly oriented to affect the volume and rheology of bronchial secretions: results are variable, and these medications tend to prove more effective in CF-related bronchiectasis.

- Bronchodilators are only effective in the presence of a degree of BHR, and also ICS are more active in these circumstances.

- Antimicrobics represent the most used class of drugs, and Tobramycin at present represents the gold standard for treating the frequently-occurring infectious exacerbations which characterise the natural history of bronchiectasis.

- In strategic terms, earlier the intervention on airway colonisation (mainly due to Pseudomonas Aeruginosa or other Gramnegative pathogens), better the outcomes and the patient's health status will be.

- Both the effectiveness and the safety of nebulised treatments are dependent of the physical characteristics of the solutions to inhale and of preservatives contained.

- Osmolality, $\mathrm{pH}$, chloride concentration of solutions, together with the heterogeneity and particle size of the aerosol emitted still represent critical points, being also crucial the role of the device to adopt.

- The role and the effectiveness of aerosol gene transfer are still debated and short-lasting at present even though the genetic approach to bronchiectasis is in progress and it will represent a true improvement in the future. 
the existence of a long lasting colonisation of respiratory tract; the resistance of resident pathogens to antimicrobic agents (in particular Pseudomonas Aeruginosa), and the immunologic patient's condition.

Other relevant factors are related to the tools and the procedures adopted for delivering medications, such as the device used for drug inhalation; the physical characteristics of solutions to inhale; both related safety and duration of the therapeutic strategy, which should be planned for a long-term period.

Outcomes are still frequently described as poorer than expected, and specific long-term trials are still needed for defining more precisely each relative therapeutic role for different class of drugs to use for managing bronchiectasis, alone or in combination.

Further research is also needed in order to maximise the encouraging results, mainly obtained in the last years with aerosilised anti-inflammatory and antimicrobic treatments for bronchiectasis, and particularly for $\mathrm{CF}$ bronchiectasis, where the efficacy and the effectiveness of aerosol gene therapy are supposed to increase rapidly in the next future also in long-term strategies.

\section{References}

1. Barker AF. Bronchiectasis. Semin Thorac Cardiovasc Surg 1995; 7: 112-8.

2. Rosen MJ. Chronic cough due to bronchiectasis - ACCP Evidence-based Clinical Practice Guidelines. Chest 2006; 129 (suppl 1): 122-31s.

3. Kondili E.; Georgopoulos D. Aerosol medications. Respir Care Clin North Am 2002; 8: 309-34.

4. Scheuch HP. Perspective in the inhalative administration of drugs. Pneumologie 2008; 62: 330-6.

5. Martinez Garcia MA, Maiz Carro L, de Garcia Roldan J. Bronchiectasis treatment in adults. Med Clin 2009; 133: 433-40.

6. O'Donnell AE, Barker AF, Ilowite JS, Fick RB. Treatment of idiopathic bronchiectasis with aerosilized recombimbinant DNase. Chest 1998; 113: 1329-34.

7. Willis J, Wodehouse T, Corkery K, Mallon K, Wilson R, Cole PJ. Short-term recombinant human DNase in bronchiectasis: effect on clinical state and in-vitro sputum transportability. Am J Respir Crit Care Med 1996; 154: 413-7.

8. Jones A, Wallis CE, Keamey CE. Recombinant human deoxiribonuclease for cystic fibrosis. Cochrane Database Syst Rev issue 2, 2004.

9. Fitzgerald DA, Hilton J, Jepson B, Smith L. A crossover, randomized, controlled trial of dornase alpha before versus after physiotherapy in cystic fibrosis. Pediatrics 2005; 116: 549-54.

10. Stafanger G, Garne S, Howitz P. The clinical effect and the effect on the ciliary motility of oral $\mathrm{N}$-acetylcysteine in patients with cystic fibrosis and primary ciliary dyskinesia. Eur Respir J 1988; 1: 161-7.

11. App EM, Baran D, Dab I, et al. Dose-finding and 24-h monitoring for efficacy and safety of aerosilised Nacystalyn in cystic fibrosis. Eur Respir J 2002; 19: 294-302.

12. Conway JH, Fleming JS, Perring S, Holgate ST. Humidification as an adjunct to chest physiotherapy in aiding tracheo-bronchial clearance in patients with bronchiectasis. Respir Med 1992; 86: 109-14.

13. Daviskas E, Anderson SD, Eberl S, Chan H-K, Bau- tovich G. Inhalation pf dry powder mannitol improves clearance of mucus in patients with bronchiectasis. Am J Respir Crit Care Med 1999; 159: 1843-8.

14. Willis P, Greenstone M. Inhaled hyperosmolar agents for bronchiectasis. Cochrane Database Syst Rev 2001; (2): CD002996.

15. Wills $\mathrm{P}$, Greenstone M. Inhaled hyperosmolar agents for bronchiectasis. Cochrane Database Syst Rev 2006, Apr. 19; (2): CD002996.

16. Elborn J, Johnston B, Allen F, et al. Inhaled steroids in patients with bronchiectasis. Respir Med 1992; 86: 121-4.

17. Tsang KW, Ho PL, Lam WK, et al. Inhaled fluticasone reduces sputum inflammatory indices in severe bronchiectasis. Am J Repir Crit Care Med 1998; 158: 723-7.

18. Van Haren WH, Lammers JWJ, Festen J, et al. The effects if inhaled corticosteroid budesonide on lung function and bronchial hyperresponsiveness in adult patients with cystic fibrosis. Respir Med 1995; 89: 209-14.

19. Tsang K, Tan K, Ho P, et al. Inhaled fluticasone in bronchiectasis: a 12 month study. Thorax 2006; 60: 239-43.

20. Kapur N, Bell S, Kolbe J, Chang AB. Inhaled steroids for bronchiectasis. Cochrane Database Syst Rev 2009 Jan 21; (1): CD000996.

21. Franco F, Sheikh A, Greenstone M. Short acting $\beta_{2}$ agonists for bronchiectasis. Cochrane Database Syst Rev (database online) Issue 2. 2004.

22. Sheikh A, Nolan D, Greenstone M. Long-acting $\beta_{2}$ agonists for bronchiectasis. Cochrane Database Syst Rev (database online) Issue 2. 2004.

23. Restrepo RD. Inhaled adrenergics and anticholinergics in obstructive lung disease: do they enhance mucociliary clearance? Respir Care 2007; 52: 1159-73.

24. Saito Y, Azuma A, Morimoto T. Tiotropium ameliorates symptoms in patients with chronic airawy muus hypersecretion which is resistant to macrolide therapy. Intern Med 2008; 47: 585-91.

25. Sutton PP, Gemmell HG, Innes N, Davidson J, Smith FW, Legge JS, Friend JA. Use of nebulised saline and nebulised terbutaline as an adjunct to chest physiotherapy. Thorax 1988; 43: 57-60.

26. Halfhide C, Evans H.J, Couriel J. Inhaled bronchodilators for cystic fibrosis. Cochrane Database Syst Rev 2005; (4): CD003428.

27. Halfhide C, Evans HJ, Couriel J. Inhaled bronchodilators for cystic fibrosis. Cochrane Database Syst Rev 2005; (4): CD006218.

28. Lasserson T, Holt K, Evans D. Greenstone M. Anticholinercic therapy for bronchiectasis. Cochrane Database Syst Rev 2001; (4): CD002163.

29. Saito Y, Azuma A, Morimoto T, et al. Tiotropium ameliorates symptoms in patients with chronic air way mucus hypersecretion which is resistant to macrolide therapy. Intern Med 2008; 47: 585-91.

30. Albelda SM, Wiewrodt R, Zuckerman JB. Gene therapy for lung disease: hype or hope? Ann Intern Med 2000; 132: 649-60.

31. Laube BL. The expanding role of aerosols in systemic drug delivery, gene therapy, and vaccination. Respir Care 2005; 50: 1161-76.

32. Flotte TR, Laube BL. Gene therapy in cystic fibrosis. Chest 2001; 120 (suppl 3), 124-31s.

33. Rosenecker J, Huth S, Rudolph C. Gene therapy for cystic fibrosis lung disease: current status and future perspectives. Curr Opin Mol Ther 2006; 8: 439-45.

34. Kolb M, Martin G, Medina M, Ask K, Gauldie J. Gene therapy for pulmonary disease. Chest 2006; 130: 879-84.

35. Pulmonary delivery of nucleic acids. Expert Opin Drug Deliv 2007; 4: 575-8.

36. Cole PJ. The role of nebulized antibiotics in treating serious respiratory infections. J Chemother 2001; 13: 354-62. 
37. Stockley RA, Hill SL, Burnett D. Nebulised amoxicillin in chronic purulent bronchiectasis. Clin Ther 1995; 7: 593-9.

38. Kuhn RJ. Formulation of aerosilised therapeutics. Chest 2001; 120 (suppl 3): 94-100s.

39. Kholhaufl M, Scheuch G, Haussinger K. Inhaled antibiotic therapy in bronchiectasis? Pneumologie 2004; 58: 499-504.

40. Evans D, Bara A, Greenstone M. Prolonged antibiotics for purulent bronchiectasis. Cochrane Database Syst Rev (database online) Issue 2, 2004.

41. Evans DJ, Bara A. Greenstone M. prolonged antibiotics for purulent bronchiectasis in children and adults. Cochrane Database Syst Rev 2007 Apr 18; (2): CD001392.

42. Lin HC, Cheng HF, Wang CH, Liu CY, Yu CT, Kuo HP. Inhaled gentamycin reduces airway neutrophyl activity and mucus secretion in bronchiectasis. Am J Crit Care Med 1997; 155: 2024-9.

43. Twiss J, Byrnes C, Johnson R, Holland D. Nebulized gentamycine-suitable for childhood bronchiectasis. Int J Pharm 2005; 295: 113-9.

44. Crowther Labiris NR, Holbrook AM, Chrystyn H, Macleod SM, Newhouse MT. Dry powder versus intravenous and nebulises gentamycin in cystic fibrosis and bronchiectasis. Am J Respir Crit Care Med 1999; 160: 1711-6.

45. Wood DM, Smyth AR. Antibiotic strategy for eradicating Pseudomonas aeruginosa in people with cystic fibrosis. Cochrane Database Syst Rev 2006 Jan 25; (1): CD004197.
46. Wieseman HG, Steinkamp G, Ratjen F, et al. Placebo controlled, double-blind, randomised study of aerosolised tobramycin for early treatment of pseudomonas aeruginosa colonization in cystic fibrosis. Pediatr Pulmonol 1998; 25: 88-92.

47. Rubin BK. Aerosolised antibiotics for non-cystic fibrosis bronchiectasis. J Aerosol Med 2008; 21: 71-6.

48. Melani AS, Di Gregorio A. Acute respiratory failure due to gentamycin aerosilisation. Monaldi Arch Chest Dis 1998; 53: 274-6.

49. Cheer SM, Waugh J, Noble S. Inhaled tobramycin (TOBI: a review of this use in the management of pseudomonas aeruginosa infections in patients with cystic fibrosis. Drugs 2003; 63: 2501-20.

50. Hagerman JK, Knechtel SA, Klesper ME. Tobramycin solution for inhalation in cystic fibrosis patients: a review of the literature. Expert Opin Drug Deliv 2006; 3: 71-86.

51. Dal Negro RW, Micheletto C, Tognella S, Visconti M, Turati C. Tobramycine nebulizer solution in severe COPD patients colonised with pseudomonas aeruginosa: effects on bronchial inflammation. Adv Ther 2008; 25: 1379-85.

52. Mendelman PM, Smith AL, Levy J, Weber A, Ramsey B, Davis RL. Aminoglycoside penetration, inactivation and efficacy in cystic fibrosis sputum. Am Rev Respir Dis 1985; 132: 761-5.

53. Drobnic ME, Suné P, Montoro JB, Ferrer A, Orriols R. Inhaled tobramycin in non-cystic fibrosis patients with bronchiectasis and chronic bronchial infection with Pseudomonas aeruginosa. Ann Pharmacother 2005; 39: 39-44.

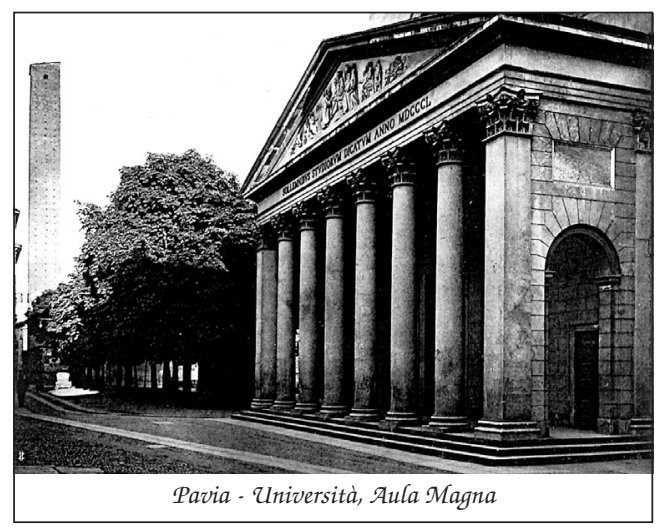

